\title{
The influence of locus of control on self-rated health in context of chronic disease: a structural equation modeling approach in a cross sectional study
}

\author{
Erik Berglund*, Per Lytsy and Ragnar Westerling
}

\begin{abstract}
Background: Self-rated health is a robust predictor of several health outcomes, such as functional ability, health care utilization, morbidity and mortality. The purpose of this study is to investigate and explore how health locus of control and disease burden relate to self-rated health among patients at risk for cardiovascular disease.

Methods: In 2009, 414 Swedish patients who were using statins completed a questionnaire about their health, diseases and their views on the three-dimensional health locus of control scale. The scale determines which category of health locus of control - internal, chance or powerful others - a patient most identifies with. The data was analyzed using logistic regression and a structural equation modeling approach.

Results: The analyses showed positive associations between internal health locus of control and self-rated health, and a negative association between health locus of control in chance and powerful others and self-rated health. High internal health locus of control was negatively associated with the cumulative burden of diseases, while health locus of control in chance and powerful others were positively associated with burden of diseases. In addition, age and education level had indirect associations with self-rated health through health locus of control.

Conclusions: This study suggests that self-rated health is positively correlated with internal locus of control and negatively associated with high locus of control in chance and powerful others in patients at high risk for cardiovascular disease. Furthermore, disease burden seems to be negatively associated with self-rated health.
\end{abstract}

Keywords: Self-rated health, Locus of control, Chronic disease, Cardiovascular disease, Diseases burden, Logistic regressions, Path model, SEM

\section{Background}

Self-rated health (SRH) is one of the most widely used measures of personal perceived health. SRH, when measured via one question, is a robust predictor of several health outcomes, such as functional ability [1,2], returning to work after coronary artery disease [3], health care utilization [4], morbidity [5,6], and mortality [7-11]. It has been shown that SRH is a more reliable predictor for future health and mental health than other more objective measures [12]. SRH is often used as an outcome measure

\footnotetext{
* Correspondence: erik.berglund@pubcare.uu.se

Department of Public Health and Caring Sciences, Uppsala University, Box 564, SE-751 22 Uppsala, Sweden
}

(c) 2014 Berglund et al.; licensee BioMed Central Ltd. This is an Open Access article distributed under the terms of the Creative Commons Attribution License (http://creativecommons.org/licenses/by/2.0), which permits unrestricted use, distribution, and reproduction in any medium, provided the original work is properly credited.

in public health-based population surveys and health service interventions because of its predictable functions.

Little is known about the mechanism behind SRH. SRH is a complex predictor and early attempts to use SRH as only a proxy for disease burden have been unsuccessful [12]; even then SRH seems to be affected by objective health to a great extent [13]. Several factors have shown associations with SRH, among them low income [14], social isolation [14], work related factors [15], psychological and social factors [15]. Possible explanations for SRH's functioning include SRH representing an individual's general perception of health, including biological, psychological and social dimensions. Therefore SRH might be more sensitive in health monitoring than other objective 
or clinical measures of health [4]. However SRH is not considered to be easily affected by temporary situations [15] and despite this, earlier studies have found that some powerful predictors of SRH are potentially modifiable [16].

Locus of control (LoC), and health locus of control, were developed from social-learning theory and refer to the degree of control that people believe they possess over their personal health [17]. Health locus of control is, in the multidimensional form, attributed to internal factors, chance, or external factors [18]. People with high internal LoC believe that their personal healthrelated outcomes are mostly determined by their own choices and actions. People with a high LoC in chance believe that their health outcomes are mostly determined by luck or chance. People with a high external LoC believe that other powerful people, such as health care providers, will determine their health outcome. LoC is considered to be quite stable over time, and the original construct was defined as a quite stable personality trait [19]. This has been further supported by clinical data [20]. Nevertheless, research also indicates that although one's overall LoC may be stable across time, changes can be seen in interventions targeting these factors with cognitive training [21]. In addition, general health education based on information, face-to-face meetings and healthy lifestyle training seems to have an impact on control feelings [22]. LoC has been shown to have an impact on risk factors, health and diseases. Gale et al. found that high internal LoC at age 10 is protective against obesity, being overweight, poor self-rated health and psychological distress at the age of 30 [23]. High internal LoC also reduced the risk of high blood pressure among women [23]. Lack of internal LoC has been associated with being overweight/obese when compared with normal weight women [24]. There are some results that indicate that $\mathrm{LoC}$ is associated with chronic diseases [25-27], SRH $[28,29]$, and mortality [30,31]. LoC beliefs have been associated with successful treatment outcomes; those patients with stronger internal beliefs had gained more from the treatment [32]. Associations between LoC and treatment adherence behavior have been found in earlier studies [33-35]. LoC as a single factor plays a modest role in explaining health behavior [36]. In some studies LoC is considered to be a mediating variable $[37,38]$. However empirical studies are inconsistent in their findings and some studies do not find any association or little explanatory power between LOC and health behavior $[39,40]$.

Living life with a chronic disease faced with long-term treatment can influence perceived health. Today, cardiovascular disease (CVD) is the most common disease and the leading cause of death in the industrialized world [41,42]. To reduce the risk for CVD, one must maintain low cholesterol levels. Statins, cholesterol lowering drugs, are therefore one of the most common long-term treatments. A not fully explored and interesting consideration is how LoC relates to SRH and diseases in a population with risk for CVD.

This study aims to investigate how health LoC and disease burden relates to SRH among patients at risk for CVD, and to explore a framework to examine how different factors are related to each other and SRH.

\section{Methods \\ Sample}

A cross-sectional design was used for this study. A total of 600 questionnaires were distributed in May 2009 to the 28 operating pharmacies within the county of Uppsala in central Sweden. The number of questionnaires distributed to each pharmacy was proportional to the number of statin prescription sales. The employees of each pharmacy were instructed to approach every patient who came in to obtain their statin prescription. There were no inclusion criteria other than the statin prescription requisite, and no exclusion criteria. After receiving oral and written information about the study by the pharmacist, patients who agreed to participate were handed a questionnaire to take home and complete, and then return by post. The number of patients declining to participate was registered for control of non-participants. The first page of the questionnaire contained precise information on the purpose of the study. Completed questionnaires were returned anonymously in a prepaid envelope. All questionnaires returned within three months were included in the study. A total of 697 statin users were asked to participate, 109 people declined participation and 588 questionnaires were handed out. One pharmacy failed to distribute their questionnaires. Questionnaires were returned by 414 individuals with a response rate for the distributed questionnaires as $70.4 \%$ (414/588) and the overall response rate 59.4\% (414/ 697). The study population consisted of slightly more men (51.0\%) than women (49.0\%). This dataset has been used in a previous study [35].

\section{Measures}

The questionnaire contained a total of 76 questions. The main data types and measures included were:

Demographic data were collected using questions that assessed the respondent's gender, age and educational level (categorized as compulsory school, secondary school or equivalent, or university).

Wallston's Multidimensional Health Locus of Control scale (MHLC) was used to determine health locus of control [18]. Respondents used a Likert scale to rate their agreement with six statements that characterized each LoC dimension: internal (I), chance (C) and powerful others (PO). Each dimension had a possible range of scores from 6 to 36 per scale. Wallston's MHLC scale is commonly used in patients with chronic diseases [43-45]. The MHLC scale 
is considered to be valid [36], and the scale has been tested in different countries [46].

Information about the patient's diseases was collected through the question: Do you have any chronic diseases, illnesses or disability or any incapability due to accident? Respondents stating "yes" were asked to specify what kind of illness using a list of 14 common health problems, including: Allergy, diabetes, symptoms of CVD, asthma/lung disease, rheumatic disease, skin disease, neurological disease, depression/mental illness, cancer and/or other chronic illness, problems following an accident or disability. These questions have been used previously [35,47]. These questions were used as a measure of disease burden which is a standard practice for studies that explore SRH [48].

SRH was assessed according to a five-point scale (very good, good, neither good nor poor, poor, very poor). In population studies, SRH is generally accepted by researchers as a valid measure to determine health status [49] with SRH also being a predictor of mortality and overall health $[10,16]$.

\section{Methodological approach and research framework}

The data was analyzed using three methods: a correlation matrix, binary logistic regressions and a structural equation modeling approach (SEM), for which a theoretical framework was constructed.

A research model of SRH influenced by disease burden and health locus of control factors (HDLoC) was constructed to examine the relationships between the variables (Figure 1). The model contains one dependent (SRH), four mediating (MHLC on three levels and disease burden), and three independent factors (gender, age and education). The research model was determined after logical reasoning considering the time factors of the variables and the previously known association presented in the introduction. MHLC is considered to be relatively stable over time $[19,20]$, unlike SRH and disease burden that reflect a more present stage. The underlying assumption in the model is that people who score highly on the internal LoC scale (those who believe that their own health behavior determines their own health status) should be more likely to carry out healthier behaviors than someone who scores low on the same scale; this should by extension lead to higher SRH and less disease burden. In the same way if someone scores high on the LoC subscale regarding chance (thus believing that luck or chance determines their health status), they should be less likely to maintain healthy behavior and by extension have lower SRH and higher disease burden.

\section{Statistical analysis}

Statistical Package for the Social Sciences (SPSS) ${ }^{\circledR}$ version 19 (Chicago, IL, USA) was used for descriptive statistics and the logistic regression and WarpPLS v. 3.0 was used for the structural equation modeling (SEM) analysis, with partial least squares estimation technique (PLS) [50]. SEM is a combination of confirmatory factor and path analysis, which allows for the inclusion of latent (not directly measured) variables [51]. Latent variables (LV) differ from observed sum-scores (index) of the indicators as they can account for measurement error in the items, and items are allowed differential weights when estimating the latent construct [52].

SEM was conducted using the PLS estimation technique with Wold's algorithm [53-55]. SEM-PLS suits the

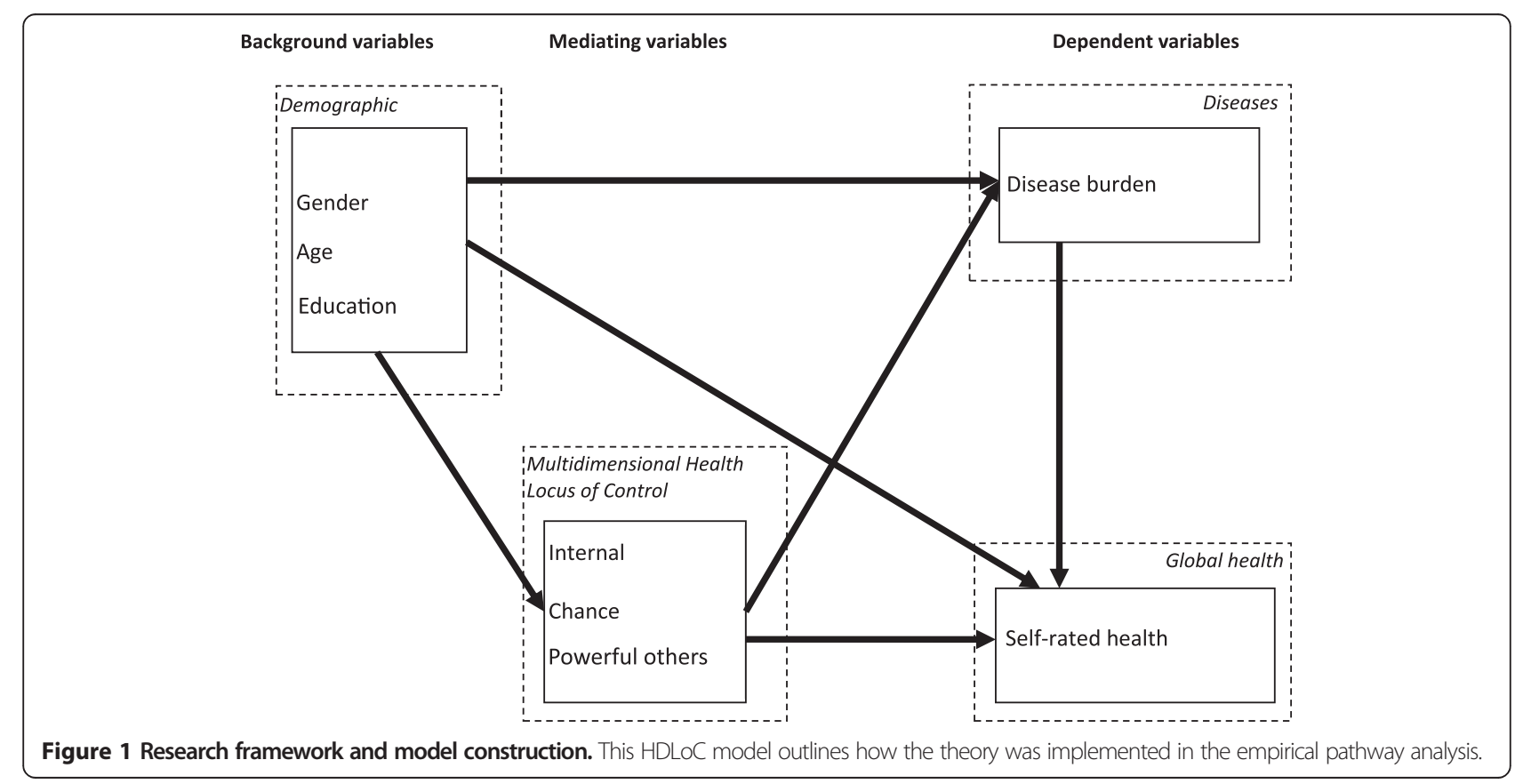


purpose for this explorative study where the primary goal was to determine which factors influence SRH, disease burden and LoC, and how they relate to each other [56]. SEM-PLS has also been used for health behavior studies [57-59]. SEM works with two models: (I) a measurement model (also called the outer model) which determines the relationships between observed variables and their association to the LV; (II) a structural model (also called the inner model), relating LV to other LV. PLS estimates loadings and path parameters between LV and maximizes the variance explained for the dependent variables. SEM-PLS allows for the opportunity to determine direct, indirect and total effect of the independent variables in the model.

Model fit indicators in WarpPLS apply to the degree of association between the observed data and the modelimplied data. In WarpPLS, the output model fit is assessed by three indices: Average path coefficient (APC), Average R-squared (ARS) and Average variance inflation factor (AVIF). APC and ARS should be under two and significant $(\mathrm{P}<0.05)$. AVIF is recommended to be lower than five.

\section{Ethical consideration}

Ethical approval was sought at the regional Ethical Committee of Clinical Investigation in Uppsala but was not deemed necessary according to Swedish law since the study group responded anonymously, leaving no possibility of individual identification.

\section{Results}

The average age of the study population was 64 years and consisted of slightly more men than women. Compulsory school was the most common education level completed. The distribution of demographics and key variables in the study population are shown in Table 1.

\section{Multidimensional health locus of control}

As can be observed in Table 1, there was a significant difference with internal and powerful others between males and females, while there was no significant difference with chance.

\section{Disease burden and SRH}

Almost $60 \%$ of the group had two diseases or less, while $7.7 \%$ of the group had five diseases or more. There was no significant difference between males and females for disease burden.

A majority (61.6\%) of patients reported good or very good global health and $7.7 \%$ reported poor or very poor global health. The last third reported neither good nor poor health. There was no significant difference between males and females for SRH.

\section{Correlation matrix and logistic regression}

Several associations outlined in the research framework (Figure 1) were significant in the correlation matrix (Table 2). The highest correlations with SRH were seen with disease burden and internal MHLC.

The background variables and $\mathrm{LoC}$ were tested using a logistic regression with SRH dichotomized into either good or less than good (Table 3). Logistic regression Model 1 tested the background variables' associations to SRH while Model 2 tested the three dimensions of MHLC with SRH. In Model 2, all dimensions of LoC had significant relationships with SRH. These results remained consistent for internal and powerful others MHLC but not for chance and then the model was adjusted with the three background variables as well as disease burden (Model 3).

\section{SEM analyses of MHLC, disease burden and SRH}

The SEM analyses of MHLC, disease burden, SRH and the demographic variables (Figure 2) showed that the three background variables were directly associated with several dimensions of LoC, but not with SRH or disease burden (Table 4).

High internal MHLC was positively associated with SRH, while high MHLC in chance and powerful others were negatively associated with SRH. Disease burden was negatively associated with internal MHLC and positively associated to chance MHLC. Disease burden also seems to lower SRH, a result that was further supported in the logistic regression (Table 3).

The total model fit indices were good with $\mathrm{APC}=$ 0.124 $(\mathrm{P}<0.001), \quad \mathrm{ARS}=0.112(\mathrm{P}<0.001)$ and $\mathrm{AVIF}=$ 1.074 .

\section{Indirect and total effects in the SEM analyses}

None of the demographic variables were directly associated with disease burden or SRH in the path model (Figure 2). However, age and education level had indirect significant associations (Table 5). Age was negatively associated with SRH and positively associated with disease burden. Having higher education was associated with having better SRH and less disease burden.

\section{Discussion}

This study aimed to explore how health LoC and disease burden are associated with SRH. Additionally, this study tested a model, HDLoC, that could contribute to the understanding and predictability of SRH, as well as SRH's association to LoC and disease burden.

Most people in this study rated their health as good or very good. Health locus of control and disease burden were strongly associated with SRH. One interesting finding was the positive association between internal MHLC and $\mathrm{SRH}$, and the negative association between internal 
Table 1 Characteristics of male and female participants

\begin{tabular}{|c|c|c|c|c|}
\hline & & Male (51\%) & Female (49\%) & Total \\
\hline \multirow[t]{2}{*}{ Age } & Mean (SD) & $63.5(10.1)$ & $64.9(8.8)$ & $64(9.5)$ \\
\hline & Compulsory school & 36.0 & 44.1 & 40.0 \\
\hline \multirow[t]{2}{*}{ Education } & Secondary school & 29.9 & 28.2 & 29.1 \\
\hline & University & 34.1 & 27.7 & 31.0 \\
\hline \multirow[t]{3}{*}{$M H L C^{a}$} & Internal (MD) & $24^{* *}$ & $22^{* *}$ & 23 \\
\hline & Chance (MD) & 16 & 17 & 17 \\
\hline & Powerful others (MD) & $20^{* *}$ & $18^{* *}$ & 19 \\
\hline \multirow[t]{4}{*}{ Disease burden (number of diseases) } & $\leq 2$ & 61.3 & 56.6 & 59.0 \\
\hline & 3 & 21.6 & 21.2 & 21.4 \\
\hline & 4 & 8.8 & 15.2 & 11.9 \\
\hline & $\geq 5$ & 8.3 & 7.1 & 7.7 \\
\hline \multirow[t]{5}{*}{ Self-rated health } & Very poor & 0.5 & 0 & 0.2 \\
\hline & Poor & 6.2 & 8.9 & 7.5 \\
\hline & Neither good nor poor & 31.4 & 25.7 & 28.6 \\
\hline & Good & 51.0 & 56.9 & 53.9 \\
\hline & Very good & 11.0 & 8.4 & 7.7 \\
\hline
\end{tabular}

Figures aspercentages if not stated otherwise.

${ }^{a}$ Multidimensional health locus of control in index-form and with median values (MD).

${ }^{* *} \mathrm{P}<0.01$.

MHLC and disease burden. This indicates that a high internal MHLC may have a direct impact on perceived health and an additional effect through disease burden, while disease burden has an association with SRH. This suggests that internal MHLC had both high indirect and total associations with SRH (Table 4). These results are consistent with other longitudinal studies on LoC [23]. Previous studies have also shown that internal health locus of control have associations with healthier choices and healthier behaviors [60], and cohort studies have shown that high internal LoC seems to be associated with a reduced risk for common chronic diseases such as CVD and cancer [27]. These results may explain some of the associations in our results. MHLC in chance seems to have the opposite relationship with health and diseases, as it lowers SRH and enlarges disease burden. High MHLC in powerful others had a negative association to SRH. Disease burden was also shown to mediate effects from both MHLC and background characteristics with SRH. This is consistent with Grotz et al.'s findings that high LoC in chance can be regarded as a risk factor for unhealthy behavior [61]. However the mechanism between LoC and SRH is not indisputable and the effect is not likely to be a non-complex function of healthy behavior.

Age and education level had no direct, but indirect, associations with disease burden and SRH. This indirect

Table 2 Correlation matrix among indicators

\begin{tabular}{|c|c|c|c|c|c|c|c|c|c|c|}
\hline & Min & Max & Std-Dev & 1 & 2 & 3 & 4 & 5 & 6 & 7 \\
\hline 1. Gender & 1 & 2 & .50 & & & & & & & \\
\hline 2. Age & 22 & 89 & 9.52 & .06 & & & & & & \\
\hline 3. Education level & 1 & 3 & .84 & -.09 & $-.27^{* *}$ & & & & & \\
\hline 4. Internal MHLC ${ }^{a}$ & 6 & 36 & 5.37 & $-.16^{* *}$ & -.05 & -.03 & & & & \\
\hline 5. Chance MHLC ${ }^{a}$ & 6 & 33 & 4.59 & .02 & $.13^{* *}$ & $-.28^{* *}$ & $.17^{* *}$ & & & \\
\hline 6. Powerful others MHLC ${ }^{a}$ & 7 & 36 & 5.26 & $-.22^{* *}$ & $.24^{* *}$ & $-.11^{*}$ & $.22^{* *}$ & $.22^{* *}$ & & \\
\hline 7. Disease burden & 0 & 9 & 1.60 & .05 & .06 & -.02 & $-.13^{* *}$ & $.14^{* *}$ & .02 & \\
\hline 8. Self-rated health & 1 & 5 & .77 & .00 & -.09 & $.10^{*}$ & $.22^{* *}$ & $-.18^{* *}$ & $-.14^{* *}$ & $-.36^{* *}$ \\
\hline
\end{tabular}

*Correlation is significant at the 0.05 level.

**Correlation is significant at the 0.01 level.

${ }^{a}$ Multidimensional health locus of control in index-form, ranging from 6 to 36 .

Maximum (max), minimum ( $\mathrm{min}$ ), standard deviations (Std-Dev) and correlations indicated. The matrix has been calculated with Spearman's correlation coefficient. An index from 6 to 36 was used for each dimension of health locus of control. 
Table 3 Logistic regressions: Associations between background variables, locus of control, disease burden and selfrated health

\begin{tabular}{|c|c|c|c|c|c|c|c|}
\hline & Variables & Nagelkerke $r^{2}$ & B & S.E. & OR & $95 \% \mathrm{Cl}$ & $\mathrm{P}$-value \\
\hline Model 1 & & 0.02 & & & & & \\
\hline \multirow[t]{3}{*}{ Background } & Gender $^{\mathrm{a}}$ & & .199 & .207 & 1.220 & 0.81 to 1.83 & 0.337 \\
\hline & Age & & -.015 & .012 & .985 & 0.96 to 1.01 & 0.199 \\
\hline & Education level & & .151 & .129 & 1.163 & 0.90 to 1.50 & 0.243 \\
\hline Model 2 & & 0.09 & & & & & \\
\hline \multirow[t]{3}{*}{ MHLC ${ }^{b}$} & Internal & & .082 & .023 & 1.085 & 1.04 to 1.14 & 0.000 \\
\hline & Chance & & -.061 & .026 & .940 & 0.89 to 0.99 & 0.017 \\
\hline & Powerful others & & -.066 & .023 & .936 & 0.90 to 0.98 & 0.004 \\
\hline Model 3 & & 0.19 & & & & & \\
\hline \multirow[t]{3}{*}{ Background } & Gender $^{\mathrm{a}}$ & & .243 & .245 & 1.275 & 0.79 to 2.06 & 0.321 \\
\hline & Age & & -.007 & .014 & .993 & 0.97 to 1.02 & 0.625 \\
\hline & Education level & & .182 & .151 & 1.200 & 0.89 to 1.61 & 0.230 \\
\hline \multirow[t]{3}{*}{$\mathrm{MHLC}$} & Internal & & .063 & .025 & 1.065 & 1.01 to 1.12 & 0.012 \\
\hline & Chance & & -.038 & .029 & .963 & 0.91 to 1.02 & 0.188 \\
\hline & Powerful others & & -.056 & .025 & .945 & 0.90 to 1.00 & 0.026 \\
\hline Diseases & Disease burden & & -.416 & .080 & .660 & 0.56 to 0.77 & 0.000 \\
\hline
\end{tabular}

${ }^{\mathrm{a}}$ Men $=1$, women $=2$.

${ }^{\mathrm{b}}$ Multidimensional health locus of control in index-form, ranging from 6 to 36 .

Odds ratio (OR), standard error (S.E.) and confidence interval (CI) for the logistic regressions.

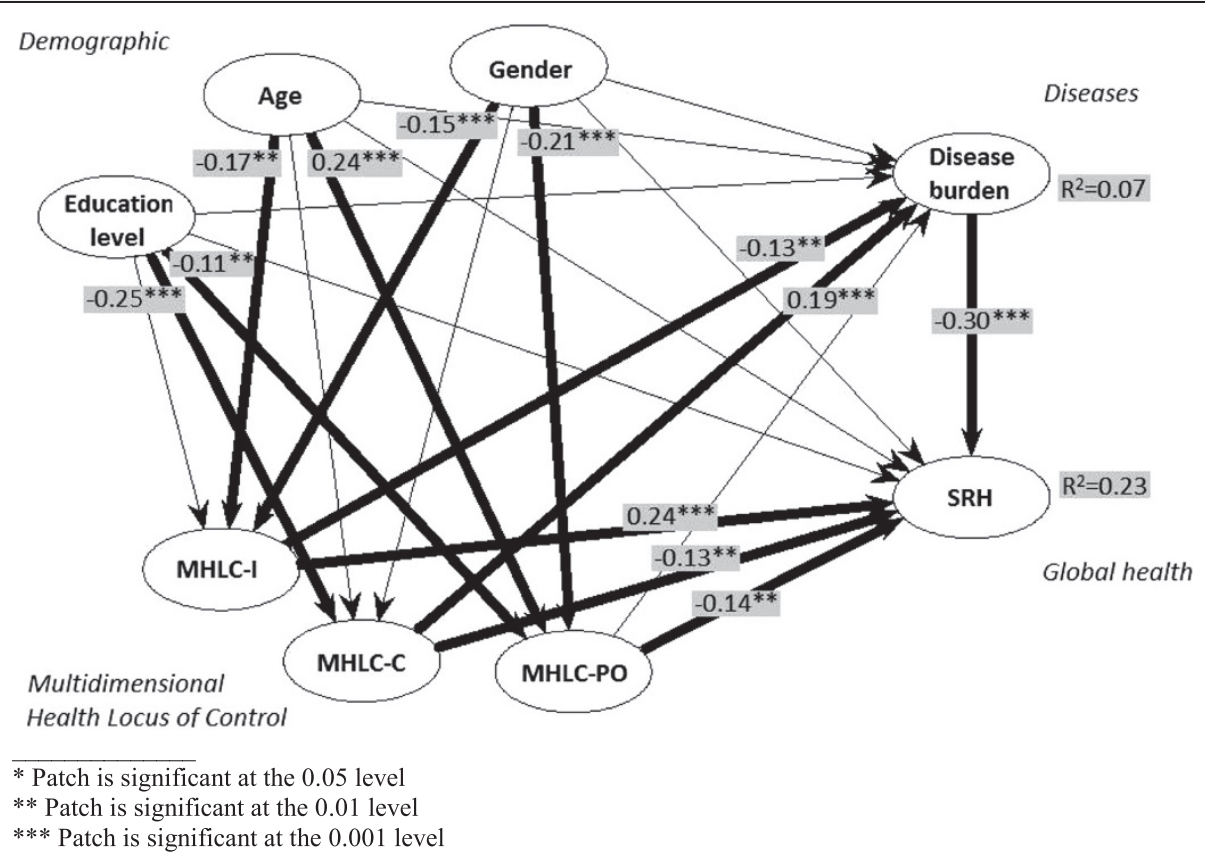

Figure 2 Structural equation model analysis of data outlined after the theoretical framework generated through a partial least squares estimation technique, with path coefficients of the pathway model (i.e. inner model). The model outlines the hypothesized relationships among the factors in the HDLOC model. Significant direct associations between latent variables are presented in bold. 
Table 4 Path coefficients and p-values of direct effects on LoC, disease burden and self-rated health

\begin{tabular}{|c|c|c|c|c|c|c|c|c|c|c|}
\hline \multirow[t]{3}{*}{ Background variables } & \multicolumn{8}{|c|}{ Mediating variables } & \multirow{2}{*}{\multicolumn{2}{|c|}{$\begin{array}{c}\text { Dependent variable } \\
\text { Self-rated health }\end{array}$}} \\
\hline & \multicolumn{2}{|c|}{ MHLC-I ${ }^{a}$} & \multicolumn{2}{|c|}{ MHLC-C ${ }^{a}$} & \multicolumn{2}{|c|}{ MHLC-PO $^{a}$} & \multicolumn{2}{|c|}{ Disease burden } & & \\
\hline & PC & p-value & PC & p-value & PC & $\overline{p \text {-value }}$ & PC & p-value & PC & p-value \\
\hline Gender & -0.15 & $<0.001$ & -0.04 & N.s. ${ }^{b}$ & -0.209 & $<0.001$ & 0.04 & N.s. ${ }^{b}$ & 0.02 & N.s. ${ }^{b}$ \\
\hline Age & -0.17 & 0.004 & 0.12 & 0.010 & 0.24 & $<0.001$ & 0.08 & N.s. ${ }^{b}$ & -0.05 & N.s. ${ }^{b}$ \\
\hline Education level & -0.05 & N.s. ${ }^{b}$ & -0.25 & $<0.001$ & -0.109 & 0.008 & 0.02 & N.s. ${ }^{b}$ & 0.03 & N.s. ${ }^{b}$ \\
\hline MHLC-1 $\left.\right|^{a}$ & & & & & & & -0.13 & 0.002 & 0.24 & $<0.001$ \\
\hline MHLC-C ${ }^{a}$ & & & & & & & 0.19 & $<0.001$ & -0.14 & 0.002 \\
\hline MHLC-PO ${ }^{a}$ & & & & & & & 0.06 & N.s. & -0.14 & 0.002 \\
\hline Disease burden & & & & & & & & & -0.30 & $<0.001$ \\
\hline
\end{tabular}

${ }^{a}$ Multidimensional health locus of control in intern $(-I)$, chance $(-C)$ and powerful other (-PO).

${ }^{\mathrm{b}}$ Not significant.

Path coefficients (PC) for direct effects in the structural equation model.

association was through MHLC, suggesting that MHLC mediates the effect of age and education. Earlier studies have shown that LoC has varied with age [62] with those older acknowledging the importance of external sources of control and at the same time preserving their sense of internal control [63]. Our study found that higher education has negative associations with chance and powerful others MHLC. Previous studies have also found that a high level of education is associated with lower scores on the external scales [64]. Higher education seems to lower disease burden and increase SRH through MHLC. Age has the opposite association. These results are only apparent in the SEM, and not in the logistic regression, which only measures direct effects. From a methodological point of view, these results indicate that it is important to measure indirect effects in order to see how the variables are associated with each other in a model.

The HDLoC model (Figure 1) was created to test associations of demographics and health locus of control on disease burden and SRH. It can be discussed whether the directions or causality arrows in the model are appropriate. This was a cross-sectional study and therefore the directions were based on logical reasoning and the chronology with which these factors are assumed to have.

The variables outlined in the HDLoC model could explain $23 \%$ of the variance in SRH, which leaves $77 \%$ unexplained variance in SRH that is dependent on factors which were not assessed in this model. This indicates that there are other variables which impact SRH. There are other variables which have an impact on SRH and it may not be unexpected that SRH is perhaps the most inclusive measure of health reflecting measures available to date, and for this reason SRH has a high predictive capacity for survival which are not covered by other health indicators [29]. However, the SEM model could explain more of the variance in SRH than the logistic regression model.

In order to test a population with chronic disease, patients visiting a pharmacy to receive their statin treatment were used as the sample population. This resulted in a high response rate and a sample population with a relatively high age. Patients with poor adherence to statins are likely to be underrepresented in this study group. Report bias may exist due to the nature of self-reported data.

Table 5 Indirect and total effects on disease burden and self-rated health

\begin{tabular}{|c|c|c|c|c|c|c|c|c|}
\hline & \multicolumn{4}{|c|}{ Disease burden } & \multicolumn{4}{|c|}{ Self-rated health } \\
\hline & \multicolumn{2}{|c|}{ Indirect effects } & \multicolumn{2}{|c|}{ Total effects } & \multicolumn{2}{|c|}{ Indirect effects } & \multicolumn{2}{|c|}{ Total effects } \\
\hline & PC & $p$-value & PC. & p-value & PC. & p-value & PC. & $\mathrm{p}$-value \\
\hline Gender & 0.01 & N.s. ${ }^{b}$ & 0.05 & N.s. ${ }^{b}$ & -0.02 & N.s. ${ }^{b}$ & 0.00 & N.s. ${ }^{b}$ \\
\hline Age & 0.06 & 0.026 & 0.14 & N.s. ${ }^{b}$ & -0.13 & 0.002 & -0.18 & N.s. ${ }^{b}$ \\
\hline Education level & -0.05 & 0.012 & -0.03 & N.s. ${ }^{b}$ & 0.04 & 0.034 & 0.07 & N.s. ${ }^{b}$ \\
\hline $\mathrm{MHLC}-\left.\right|^{a}$ & & & & & 0.04 & 0.010 & 0.28 & $<0.001$ \\
\hline $\mathrm{MHLC}-\mathrm{C}^{\mathrm{a}}$ & & & & & -0.06 & $<0.001$ & -0.19 & $<0.001$ \\
\hline MHLC-PO ${ }^{a}$ & & & & & -0.02 & N.s. ${ }^{b}$ & -0.16 & 0.001 \\
\hline
\end{tabular}

${ }^{a}$ Multidimensional health locus of control in intern $(-I)$, chance $(-C)$ and powerful other (-PO).

${ }^{\mathrm{b}}$ Not significant.

Path coefficients (PC) for indirect and total effects in the structural equation model. 
This study suggests that it may be possible to increase an individual's perceived health and lower disease burden by managing $\mathrm{LoC}$ and factors that are related to LoC. Although LoC is quite stable over time and not easy to change, targeted interventions have demonstrated changes in LoC [21]. More research is needed to determine if these types of changes are stable or if health LoC returns to its original level over time. This study also highlights the importance of disease burden for perceived health, and that LoC factors probably are important for both perceived health and the development of diseases, which also seems to be important for perceived health. The results of this study suggest that an approach targeting LoC might be able to increase SRH. However LoC is not assumed to be easily affected as it is considered to be partly a trait-like and partly a state-like measure [35]. LoC is supposed to be similar in a variety of health-related situations, but may also be sensitive enough to change as a function of one's health-related experiences. In which case it will probably take a long time before a change in LoC can cause a change in SRH, as there are many mechanisms, healthy choices and behaviors that must be affected for a change to be noticeable in SRH or in disease burden. The implications of this study are primarily on a theoretical level, as more research is needed on the mechanisms underlying SRH and LoC. However this study suggests that LoC should be considered an important factor included in studies of personal perceived health, and might be beneficial to work with LoC factors in patient groups with longterm diseases.

\section{Conclusion}

This study suggests that SRH is positively associated with internal health locus of control and negatively associated with chance and powerful others health locus of control, as well as disease burden. Disease burden is negatively associated with internal health locus of control but positively associated with chance health locus of control.

\section{Abbreviations}

APC: Average path coefficient; ARS: Average R-squared; AVIF: Average variance inflation factor; CVD: Cardiovascular disease; HDLoC: Self-rated Health influenced by Disease burden and health Locus of Control factors; LoC: Locus of Control; LV: Latent variables; MHLC: Multidimensional Health Locus of Control; PLS: Partial least squares; SEM: Structural equation modeling; SRH: Self-rated health; SPSS: Statistical Package for the Social Sciences.

\section{Competing interests}

The authors declare that they have no competing interests.

\section{Authors' contributions}

EB designed the study, undertook the statistical modeling and led the writing. PL and RW designed the study, contributed to data interpretation, and commented on successive drafts of the manuscript and handling of data. All authors approved the final version of the manuscript.

\section{Acknowledgments}

We would like to acknowledge the National Corporation of Swedish Pharmacies and the staff at the pharmacies in Uppsala for their assistance with the distribution of questionnaires. We are also grateful to all the respondents for sharing their views about their health and health beliefs.

Received: 5 June 2013 Accepted: 19 May 2014

Published: 23 May 2014

\section{References}

1. Idler EL, Russell LB, Davis D: Survival, functional limitations, and self-rated health in the NHANES I Epidemiologic Follow-up Study, 1992. First National Health and Nutrition Examination Survey. Am J Epidemiol 2000, 152(9):874-883.

2. Idler EL, Kasl SV: Self-ratings of health: do they also predict change in functional ability? J Gerontol B Psychol Sci Soc Sci 1995, 50(6):S344-S353.

3. Bergvik S, Sorlie T, Wynn R: Coronary patients who returned to work had stronger internal locus of control beliefs than those who did not return to work. Br J Health Psychol 2012, 17(3):596-608.

4. Miilunpalo S, Vuori I, Oja P, Pasanen M, Urponen H: Self-rated health status as a health measure: the predictive value of self-reported health status on the use of physician services and on mortality in the working-age population. J Clin Epidemiol 1997, 50(5):517-528.

5. Kaplan GA, Goldberg DE, Everson SA, Cohen RD, Salonen R, Tuomilehto J, Salonen J: Perceived health status and morbidity and mortality: evidence from the Kuopio ischaemic heart disease risk factor study. Int J Epidemiol 1996, 25(2):259-265.

6. Emmelin M, Weinehall L, Stegmayr B, Dahlgren L, Stenlund H, Wall S: Selfrated ill-health strengthens the effect of biomedical risk factors in predicting stroke, especially for men - an incident case referent study. $J$ Hypertens 2003, 21(5):887-896.

7. Idler EL, Benyamini Y: Self-rated health and mortality: a review of twenty-seven community studies. J Health Soc Behav 1997, 38(1):21-37.

8. DeSalvo KB, Bloser N, Reynolds K, He J, Muntner P: Mortality prediction with a single general self-rated health question. A meta-analysis. $J$ Gen Intern Med 2006, 21(3):267-275.

9. Singh-Manoux A, Gueguen A, Martikainen P, Ferrie J, Marmot M, Shipley M: Self-rated health and mortality: short- and long-term associations in the Whitehall II study. Psychosom Med 2007, 69(2):138-143.

10. Mossey JM, Shapiro E: Self-rated health: a predictor of mortality among the elderly. Am J Public Health 1982, 72(8):800-808.

11. Siegel M, Bradley EH, Kasl SV: Self-rated life expectancy as a predictor of mortality: evidence from the HRS and AHEAD surveys. Gerontology 2003, 49(4):265-271.

12. Strawbridge WJ, Wallhagen MI: Self-rated health and mortality over three decades results from a time-dependent covariate analysis. Research on Aging 1999, 21(3):402-416.

13. Wu S, Wang R, Zhao Y, Ma X, Wu M, Yan X, He J: The relationship between self-rated health and objective health status: a population-based study. BMC Public Health 2013, 13:320.

14. Heritage Z, Wilkinson RG, Grimaud O, Pickett KE: Impact of social ties on self reported health in France: is everyone affected equally? BMC Public Health 2008, 8:243.

15. Hasson D, Arnetz BB, Theorell T, Anderberg UM: Predictors of self-rated health: a 12-month prospective study of IT and media workers. Popul Health Metr 2006, 4:8

16. Lorraine PJ, Hammock RL, Blanton JM: Predictors of self-rated health status among Texas residents. Prev Chronic Dis 2005, 2(4):A12.

17. Rotter JB: Social learning and clinical psychology. Englewood Cliffs, NJ: Prentice-Hall; 1954

18. Wallston KA, Wallston BS, DeVellis R: Development of the Multidimensional Health Locus of Control (MHLC) Scales. Health Educ Monogr 1978, 6(2):160-170.

19. Rotter J: Generalized expectancies for internal versus external control of reinforcements. Psychological Monographs 1966, 609(80):1-28.

20. Layton C: Note on the stability of Rotter's I-E Scale. Psychol Rep 1985, 57(3):1165-1166

21. Wolinsky FD, Vander Weg MW, Martin R, Unverzagt FW, Willis SL, Marsiske M, Rebok GW, Morris JN, Ball KK, Tennstedt SL: Does cognitive training improve internal locus of control among older adults? J Gerontol B Psychol Sci Soc Sci 2010, 65(5):591-598. 
22. Bastani F, Hashemi S, Bastani N, Haghani H: Impact of preconception health education on health locus of control and self-efficacy in women. East Mediterr Health J 2010, 16(4):396-401.

23. Gale CR, Batty GD, Deary IJ: Locus of control at age 10 years and health outcomes and behaviors at age 30 years: the 1970 British Cohort Study. Psychosom Med 2008, 70(4):397-403.

24. Ali SM, Lindstrom M: Socioeconomic, psychosocial, behavioural, and psychological determinants of BMI among young women: differing patterns for underweight and overweight/obesity. Eur J Public Health 2006, 16(3):325-331.

25. Neylon A, Canniffe C, Anand S, Kreatsoulas C, Blake GJ, Sugrue D, McGorrian C: A global perspective on psychosocial risk factors for cardiovascular disease. Prog Cardiovasc Dis 2013, 55(6):574-581.

26. Henninger DE, Whitson HE, Cohen HJ, Ariely D: Higher medical morbidity burden is associated with external locus of control. J Am Geriatr Soc 2012, 60(4):751-755.

27. Sturmer T, Hasselbach P, Amelang M: Personality, lifestyle, and risk of cardiovascular disease and cancer: follow-up of population based cohort. BMJ 2006, 332(7554):1359.

28. Lundberg J, Bobak M, Malyutina S, Kristenson M, Pikhart H: Adverse health effects of low levels of perceived control in Swedish and Russian community samples. BMC Public Health 2007, 7:314.

29. Ward MM: Sense of control and self-reported health in a population-based sample of older Americans: assessment of potential confounding by affect, personality, and social support. Int J Behav Med 2013, 20(1):140-147.

30. Bosma H, Schrijvers C, Mackenbach JP: Socioeconomic inequalities in mortality and importance of perceived control: cohort study. BMJ 1999, 319(7223):1469-1470.

31. Mackenbach JP, Simon JG, Looman CW, Joung IM: Self-assessed health and mortality: could psychosocial factors explain the association?. Int J Epidemiol 2002, 31(6):1162-1168.

32. Harkapaa K, Jarvikoski A, Mellin G, Hurri H, Luoma J: Health locus of control beliefs and psychological distress as predictors for treatment outcome in low-back pain patients: results of a 3-month follow-up of a controlled intervention study. Pain 1991, 46(1):35-41.

33. Morowatisharifabad MA, Mahmoodabad SS, Baghianimoghadam MH, Tonekaboni NR: Relationships between locus of control and adherence to diabetes regimen in a sample of Iranians. Int J Diabetes Dev Ctries 2010, 30(1):27-32

34. Omeje $\mathrm{O}$, Nebo $\mathrm{C}$ : The influence of locus control on adherence to treatment regimen among hypertensive patients. Patient Prefer Adherence 2011, 5:141-148

35. Berglund E, Lytsy P, Westerling R: Adherence to and beliefs in lipid-lowering medical treatments: A structural equation modeling approach including the necessity-concern framework. Patient Educ Couns 2013, 91(1):105-112.

36. Wallston KA: The Validity of the Multidimensional Health Locus of Control Scales. J Health Psychol 2005, 10(5):623-631.

37. Carlisle-Frank P: Examining personal control beliefs as a mediating variable in the health-damaging behavior of substance use: an alternative approach. J Psychol 1991, 125(4):381-397.

38. Rowe JL, Montgomery GH, Duberstein PR, Bovbjerg DH: Health locus of control and perceived risk for breast cancer in healthy women. Behav Med 2005, 31(1):33-40.

39. Calnan M: Control over health and patterns of health-related behaviour. Soc Sci Med 1989, 29(2):131-136.

40. Bennett P, Norman P, Murphy S, Moore L, Tudor-Smith C: Beliefs about alcohol, health locus of control, value for health and reported consumption in a representative population sample. Health Educ Res 1998, 13(1):25-32.

41. Michaud CM, Murray CJ, Bloom BR: Burden of disease-implications for future research. JAMA: The J Am Medical Association 2001, 285(5):535-539.

42. Remme WJ, Swedberg K: Guidelines for the diagnosis and treatment of chronic heart failure. Eur Heart J 2001, 22(17):1527-1560.

43. Fowers BJ: Perceived control, illness status, stress, and adjustment to cardiac illness. J Psychol 1994, 128(5):567-576.

44. Trento M, Passera P, Miselli V, Bajardi M, Borgo E, Tomelini M, Tomalino M, Cavallo F, Porta M: Evaluation of the locus of control in patients with type 2 diabetes after long-term management by group care. Diabetes Metab 2006, 32(1):77-81.

45. O'Hea EL, Moon S, Grothe KB, Boudreaux E, Bodenlos JS, Wallston K, Brantley PJ: The interaction of locus of control, self-efficacy, and outcome expectancy in relation to $\mathrm{HbA} 1 \mathrm{c}$ in medically underserved individuals with type 2 diabetes. J Behav Med 2009, 32(1):106-117.

46. Kuwahara A, Nishino Y, Ohkubo T, Tsuji I, Hisamichi S, Hosokawa T: Reliability and validity of the Multidimensional Health Locus of Control Scale in Japan: relationship with demographic factors and health-related behavior. Tohoku J Exp Med 2004, 203(1):37-45.

47. Lytsy $P$, Westerling R: Patient expectations on lipid-lowering drugs. Patient Educ Couns 2007, 67(1-2):143-150.

48. Micciolo R, Canal L, Minniti A, Mazzali G, Fantin F, Corzato F, Antonioli A, Harris TB, Zamboni M: The association between excess weight and comorbidity and self-rated health in the Italian population. Ann Epidemiol 2013, 4:172-178.

49. Lundberg O, Manderbacka K: Assessing reliability of a measure of self-rated health. Scand J Soc Med 1996, 24(3):218-224.

50. Kock N: WarpPLS 2.0 User Manual. Laredo, Texas: ScriptWarp Systems; 2011.

51. Tomarken AJ, Waller NG: Structural equation modeling: strengths, limitations, and misconceptions. Annu Rev Clin Psychol 2005, 1:31-65.

52. Skrondal A, Rabe-Hesketh S: Generalized linear latent and mixed models with composite links and exploded likelihoods. In Statistical modelling. Edited by Biggeri A, Dreassi E, Lagazio C, Marchi M. Firenze: Firenze University Press; 2004:27-39.

53. Wold H: Nonlinear Iterative Partial Least Squares (NIPALS) modeling: some current developments. In Multivariate Analysis. Edited by Krishnaiah P. New York: Academic Press; 1973:383-407.

54. Wold H: Path models with latent variables: the NIPALS approach. In Quantitative Sociology: International Perspectives on Mathematical and Statistical Model Building. Edited by Blalock H, Aganbegian A, Borodkin F, Budon R, Capecch V. New York: Academic Press; 1975.

55. Wold S, Ruhe A, Wold H, Dunn WJ: Collinearity problem in linear regression. The partial least squares (PLS) approach to generalized inverses. SIAM J Sci Comput Stat 1984, 5:735-743.

56. Gebauer J, Kline DM, He L: Password security risk versus effort: an exploratory study on user-perceived risk and the intention to use online applications. Journal of Information Systems Applied Research 2011, 4(2):52-62.

57. Maikranz JM, Steele RG, Dreyer ML, Stratman AC, Bovaird JA: The relationship of hope and illness-related uncertainty to emotional adjustment and adherence among pediatric renal and liver transplant recipients. J Pediatr Psychol 2007, 32(5):571-581.

58. Byrne MK, Deane FP: Enhancing patient adherence: outcomes of medication alliance training on therapeutic alliance, insight, adherence, and psychopathology with mental health patients. Int J of Mental Health Nnursing 2011, 20(4):284-295.

59. Chan DK, Fung YK, Xing S, Hagger MS: Myopia prevention, near work, and visual acuity of college students: integrating the theory of planned behavior and self-determination theory. J Behav Med 2014, 37(3):369-380.

60. Helmer SM, Kramer A, Mikolajczyk RT: Health-related locus of control and health behaviour among university students in North Rhine Westphalia, Germany. BMC Res Notes 2012, 5:703.

61. Grotz M, Hapke U, Lampert T, Baumeister H: Health locus of control and health behaviour: results from a nationally representative survey. Psychol Health Med 2011, 16(2):129-140.

62. Bailis DS, Segall A, Chipperfield JG: Age, relative autonomy and change in health locus of control beliefs: a longitudinal study of members of a health-promotion facility. J Health Psychol 2010, 15(3):326-338.

63. Lachman ME: Locus of control in aging research: a case for multidimensional and domain-specific assessment. Psychol Aging 1986, 1(1):34-40.

64. Sørlie T, Sexton HC: Predictors of change in health locus of control following surgical treatment. Personal Individ Differ 2004, 36(5):991-1004.

doi:10.1186/1471-2458-14-492

Cite this article as: Berglund et al:: The influence of locus of control on self-rated health in context of chronic disease: a structural equation modeling approach in a cross sectional study. BMC Public Health 2014 14:492. 